\title{
Production Time Optimization using Campbell Dudek Smith (CDS) Algorithm for Production Scheduling
}

\author{
Chamdan Mashuri ${ }^{1, *}$, Ahmad Heru Mujianto ${ }^{1}$, Hadi Sucipto $^{3,}$ Rinaldo Yudianto Arsam ${ }^{2}$, and Ginanjar Setyo Permadi ${ }^{3}$ \\ ${ }^{1}$ Information System Department of Information Technology Faculty, Hasyim Asy'ari University, Jombang - Indonesia \\ ${ }^{2}$ Informatics Engineering Department of Information Technology Faculty, Hasyim Asy'ari University, Jombang - Indonesia \\ ${ }^{3}$ Informatics Management Department of Information Technology Faculty, Hasyim Asy'ari University, Jombang - Indonesia
}

\begin{abstract}
The production time optimization study used the Campbell Dudek smith (CDS) algorithm in the production process scheduling aimed at makespan optimization for engine operation to produce 12-size pan products, 14-size griddle, 16-size griddle, 18-size griddle, and 20-size griddle. The method applied by the Campbell Dudek and Smith (CDS) algorithm, CDS is a method used in flowshop-type scheduling developed from Johnson's rule that is able to minimize makespan 2 machines arranged in series. The CDS method is very suitable for production characters who apply the machine sequence to the production process. CDS produces several iterations that have makespan values, from the few iterations the most minimum makespan value is obtained to determine the order of products to be produced. This research produces an application that can schedule products to be produced by the machine automatically. From the results of testing with a total production of 12 pieces on each product with repetitions of 6 times, the minimum makespan value is 210.12 minutes with a work order of 20 , grid 18 , griddle 16 , griddle 14 , and griddle 12. Accuracy of results Application testing showed $99.99 \%$ for the first time and $99.96 \%$ for the second time when compared to manual calculations.
\end{abstract}

Keywords: Optimization; production; scheduling; CDS; makespan.

\section{Introduction}

The modern production industry provides scheduling as the main core of the production process. Production scheduling is the process of allocating existing resources or machines to run a set of tasks within a certain period of time. Scheduling needs to be designed according to the characteristics of the production line. The basic work of scheduling is to process tasks according to the processing process to regulate production and processing. The purpose of scheduling is to arrange production tasks to devices in a process because scheduling has many processes, many stations, many obstacles, and rules. Production scheduling is very important for companies that use the make to order system, where new products will be produced at the request of consumers [1].

Scheduling is a serious problem in the production process known as a complex problem. One of the controls and production scheduling planning that is able to solve scheduling problems is by optimizing production time. The main objective of the optimization is management to develop a scheduling policy that can minimize the total production time and makespan. Production scheduling optimization is an important factor in the production process, one of which affects production scheduling is the production time of each machine and irregular production demand [2].
Optimization is the best performance in an industrial process known as optimal operation. In manufacturing it can be said to be a product optimization process. Optimization is able to have a positive impact on producers and consumers. Producers have an optimal time to produce goods so that the production process of goods is more effective. Consumers will be edited by knowing the processing time of goods has been completed without delay [3].

Optimization is able to search and resolve one or more of the value values of one or more objective functions on a problem so that optimal value is obtained. Optimization aims to improve the performance of production machinery so that it has good quality and high work results [4].

Production optimization is needed by the company in order to optimize the resources used so that production can produce the product in the expected quantity and quality, so the company can achieve its objectives. Production optimization is the use of production factors that are as efficient as possible. These production factors are capital, machinery, equipment, raw materials, auxiliary materials, and labor. An optimization is a normative approach by identifying the best solution to a problem directed at the maximum or minimum point of an objective function [5].

Campbell Dudek Smith (CDS) is based on Johnson's algorithm. CDS is able to solve the problem of $n$ jobs in

* Corresponding author: chamdan.mashuri@gmail.com 
the flow shop engine into the $\mathrm{m}-1$ set of two machine flow shop problems by dividing the machine $m$ into two groups, then sorting the jobs on the two machines using Johnson algorithm. After obtaining as many as m-1 alternative job sequences, then the sequence is selected with the smallest makespan. Every job or job that will be completed must go through the process on each machine. In this scheduling, try to get the smallest makespan price from (m-1) the possibility of scheduling. Scheduling with the lowest makespan price is the best sequence of job processing [6].

Campbell Dudek Smith (CDS) algorithm is able to change the problem of $n$-work and the given m-machine $(m>2)$ to be the number $p$ of the 2-engine $n$-job replacement problem, where $\mathrm{p}=\mathrm{m}-1$. Each replacement problem is resolved using Johnson rules. The Cmax value for each replacement problem is found using Johnson rules. The sequence of replacement problems produces a minimum value of Cmax after applying Johnson's rule chosen to schedule work on the machine [7].

Supply Chain Management (SCM) is able to regulate, plan, control, and realize the flow of products, from designing and buying through production and distribution to end consumers. SCM is able to meet the demand for company products significantly better and significantly reduce logistics and purchasing costs. SCM covers the entire cycle of purchasing raw materials, producing and distributing products. SCM can be identified with six main areas that are the focus of supply chain management, namely production, inventory, location, warehouse inventory, transportation, and information [8].

SCM is able to provide solutions by making optimal plans for the use of existing technology lines and detailing what, when and what sequence must be made taking into account the limitations of capacity, raw materials and materials to replace equipment to produce new products. SCM helps achieve high demand satisfaction with minimum costs. The implementation of SCM enables companies to gain competitive advantages such as reducing costs and processing time by $20-40 \%$, reducing purchasing costs by $5-15 \%$, reducing production costs by $5-15 \%$ and increasing profits by $5-$ $15 \%$ [8].

Well-functioning SCM can help improve the planning system, optimize warehouse inventory, and make SCM include planning and management of all activities involved in procurement, conversion, and all logistics management activities. SCM can coordinate and collaborate with partners that can be done such as suppliers, intermediaries, third-party service providers, and customers. In essence, Amapu SCM integrates management supply and demand within and throughout the company [9].

\section{Methods}

\subsection{System flow}

This stage is made as a benchmark of system development. The system flow is described in the form of block diagrams which are used as a general description of the process of running the system, in Fig. 1 .

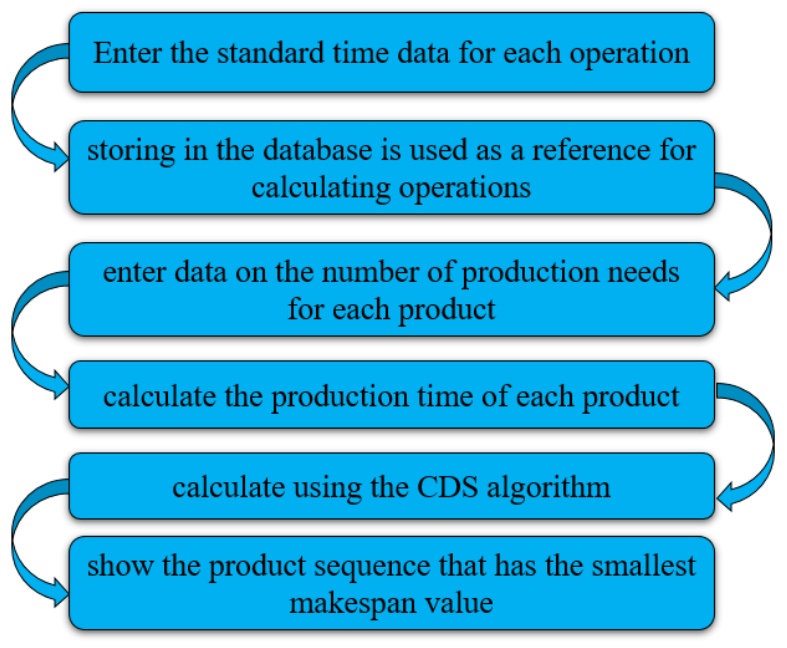

Fig. 1. System flow block diagram

\subsection{Modeling with CDS}

The work scheduling process on Campbell, Dudek and Smith algorithms is based on the smallest working time used in production. In this problem, $\mathrm{n}$ jobs and $\mathrm{m}$ machines are used. CDS decides for the first sequence, 1 $=\mathrm{ti}, 1$ and $\mathrm{tki}, 1=\mathrm{ti}, \mathrm{m}$ as the processing time on the first machine and the last machine.

$$
\begin{gathered}
t^{k} k_{i, 1}=t_{i_{m} 1}+t_{i_{m}, 2} \\
t^{k} k_{i, 2}=t_{i m m}+t_{i_{m} m-1}
\end{gathered}
$$

As the processing time on the first two machines and the last two machines for the sequence $\mathrm{k}$

$$
\begin{aligned}
t^{k} k_{i, 1} & =\sum_{j=1}^{k} t_{i, j} \\
t^{k} k_{i, 2} & =\sum_{j=m+1-k}^{k} t_{i, j}
\end{aligned}
$$

The description of the variable in the formula above that $i$ is the job, $j$ is the machine, $t^{k}$ is the processing time of the first and first job while $t^{k}{ }_{i 2}$ is The processing time for a second job and a second machine and $\mathrm{m}$ is the number of machines used, and $\mathrm{k}$ is an iteration $(\mathrm{k}=1,2$, $3, \ldots(\mathrm{m}-1))$.

The following is the Campbell Dudek and Smith flowchart (CDS) algorithm design flowchart that is applied in the system and will serve as a scheduling determination. The steps begin by determining the number $\mathrm{i}$ (job) and $\mathrm{m}$ (machine) and proceed with finding the value $\mathrm{k}$ until determining the minimum value as detailed in Fig. 2. 


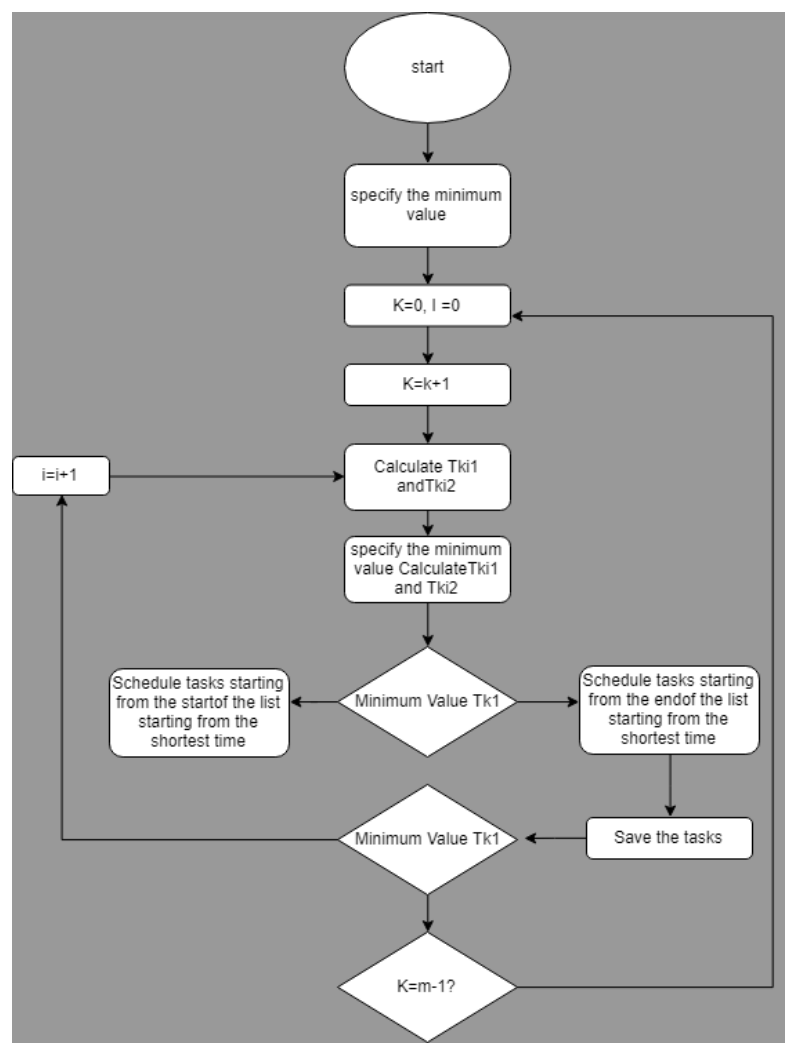

Fig. 2. Flowchart Algoritma CDS

\section{Results and Discussion}

Standard time is used as the average time used by the company to work on a product on a machine used by the company, each product that will be produced through the machine in the same order. The machine used by the company to complete the production of a product has 7 machines, namely printing machines, checking machines, thought machines, turning machines, checking machines, labeling machines, and finishing machines. Each machine has a different average time according to the product processed by the machine, and that time will be used as the system standard time obtained from the results of data analysis, which can be seen in Table 1 . While the ready time is the time obtained from the multiplication of the standard time with the number of products to be produced, the number of products to be produced is used as many as 12 products per type of pan which can be seen in Table 2 .

Table 1. Standard time

\begin{tabular}{|c|c|c|c|c|c|}
\hline \multirow{2}{*}{$\begin{array}{c}\text { Machine } \\
\text { name }\end{array}$} & \multicolumn{5}{|c|}{ Processing time (seconds) } \\
\cline { 2 - 6 } & $\begin{array}{c}\text { Skillet } \\
12\end{array}$ & $\begin{array}{c}\text { Skillet } \\
14\end{array}$ & $\begin{array}{c}\text { Skillet } \\
16\end{array}$ & $\begin{array}{c}\text { Skillet } \\
18\end{array}$ & $\begin{array}{c}\text { Skillet } \\
20\end{array}$ \\
\hline Printing & 83.38 & 121.34 & 143.05 & 140.72 & 162.96 \\
\hline Checking & 3.79 & 4.15 & 5.04 & 5.04 & 5.92 \\
\hline Thought & 150.04 & 159.73 & 178.52 & 186.84 & 199.05 \\
\hline Turning & 134.15 & 153.82 & 154.51 & 165.60 & 174.03 \\
\hline Checking & 11.52 & 11.28 & 11.84 & 12.24 & 12.84 \\
\hline Labeling & 24.58 & 24.83 & 24.31 & 27.31 & 31.27 \\
\hline Finishing & 75.08 & 77.66 & 82.20 & 83.80 & 85.85 \\
\hline
\end{tabular}

Table 2. Ready time

\begin{tabular}{|l|c|c|c|c|c|}
\hline \multirow{2}{*}{$\begin{array}{c}\text { Machine } \\
\text { Name }\end{array}$} & \multicolumn{5}{|c|}{ Processing time (seconds) } \\
\cline { 2 - 7 } & $\begin{array}{c}\text { Skillet } \\
12\end{array}$ & $\begin{array}{c}\text { Skillet } \\
14\end{array}$ & $\begin{array}{c}\text { Skillet } \\
16\end{array}$ & $\begin{array}{c}\text { Skillet } \\
18\end{array}$ & $\begin{array}{c}\text { Skillet } \\
20\end{array}$ \\
\hline Printing & 1000.56 & 1456.04 & 1716.54 & 1688.59 & 1955.50 \\
\hline Checking & 45.46 & 49.81 & 60.44 & 60.48 & 71.05 \\
\hline Thought & 1800.47 & 1916.74 & 2142.18 & 2242.09 & 2388.59 \\
\hline Turning & 1609.75 & 1845.83 & 1854.13 & 1987.24 & 2088.32 \\
\hline Checking & 138.25 & 135.30 & 142.09 & 146.93 & 154.06 \\
\hline Labeling & 294.92 & 297.91 & 291.77 & 327.71 & 375.19 \\
\hline finishing & 901.01 & 931.86 & 986.36 & 1005.61 & 1030.14 \\
\hline
\end{tabular}

\subsection{Iteration algorithm}

The iterations obtained from the CDS algorithm with the number of machines 7 and the number of products 5 have 6 iterations, which are described below.

- Iteration 1

The following is the first and second time table of iterations 1:

Table 3. CDS first iteration

\begin{tabular}{|c|c|c|c|c|}
\hline \multirow[t]{2}{*}{ Job } & \multicolumn{2}{|c|}{$\begin{array}{l}\text { Total manual } \\
\text { processing time } \\
\text { (seconds) }\end{array}$} & \multicolumn{2}{|c|}{$\begin{array}{l}\text { Total processing time } \\
\text { (seconds) of the } \\
\text { system }\end{array}$} \\
\hline & $t^{k}{ }_{i, 1}^{K}$ & $t^{K_{1,2}}$ & $t^{K_{i, 1}}$ & $t^{K_{1,2}}$ \\
\hline 1 & 1000.56 & 901.01 & 1000.56 & 901.01 \\
\hline 2 & 1456.04 & 931.86 & 1456.04 & 931.86 \\
\hline 3 & 1716.54 & 986.36 & 1716.54 & 986.36 \\
\hline 4 & 1688.59 & 1005.61 & 1688.59 & 1005.61 \\
\hline 5 & 1955.50 & 1030.14 & 1955.50 & 1030.14 \\
\hline Total & 7817.23 & 4854.98 & 7817.23 & 4854.98 \\
\hline
\end{tabular}

The first iteration is obtained from the first and the seventh engine time. For the first iteration $(\mathrm{k}=1)$, the sequence generated from the system and manual calculation is the same, namely $5-4-3-2-1$. So that the total time is 210.12 minutes.

- Iteration 2

Following the first and second iteration in Table 2 and Table 3 . The result shown in Table 4:

Table 4. CDS second iteration

\begin{tabular}{|c|c|c|c|c|}
\hline \multirow[t]{2}{*}{ Job } & \multicolumn{2}{|c|}{$\begin{array}{l}\text { Total manual } \\
\text { processing time } \\
\text { (seconds) }\end{array}$} & \multicolumn{2}{|c|}{$\begin{array}{l}\text { Total processing time } \\
\text { (seconds) of the } \\
\text { system }\end{array}$} \\
\hline & $t^{k} k_{i 1}$ & $t^{k} k_{i, 2}$ & $t^{k_{i \mathbb{1}}}$ & $t^{k} k_{i, 2}$ \\
\hline 1 & 1045.91 & 1195.8 & 1046.02 & 1195.93 \\
\hline 2 & 1505.76 & 1229.64 & 1505.86 & 1229.77 \\
\hline 3 & 1776.84 & 1278 & 1776.98 & 1278.13 \\
\hline 4 & 1749 & 1333.19 & 1749.07 & 1333.32 \\
\hline 5 & 2026.44 & 1405.19 & 2026.55 & 1405.33 \\
\hline Total & 8103.95 & 6441.82 & 8104.48 & 6442.49 \\
\hline
\end{tabular}

The second iteration is obtained from time (engine 1 + engine 2 ) and time (engine $7+$ engine 6 ). For the second iteration $(\mathrm{k}=2)$, the sequence generated from the system and manual calculation is the same, namely $1-5-4-3-2$, so that the total time is obtained at 232.08 minutes. 
- Iteration 3

Following the first and second iteration in Table 2 and Table 3 . The result shown in Table 5:

Table 5. CDS third iteration

\begin{tabular}{|c|c|c|c|c|}
\hline \multirow[t]{2}{*}{ Job } & \multicolumn{2}{|c|}{$\begin{array}{l}\text { Total manual processing } \\
\text { time (seconds) }\end{array}$} & \multicolumn{2}{|c|}{$\begin{array}{l}\text { Total processing time } \\
\text { (seconds) of the } \\
\text { system }\end{array}$} \\
\hline & $t^{K_{i, 1}^{2}}$ & $t^{K_{i, 2}^{2}}$ & $t^{k}{ }_{i 1}$ & $t^{k}{ }_{i, 2}$ \\
\hline 1 & 2846.28 & 1334.04 & 2846.48 & 1334.18 \\
\hline 2 & 3422.39 & 1364.88 & 3422.59 & 1365.07 \\
\hline 3 & 3918.96 & 1420.08 & 3919.16 & 1420.22 \\
\hline 4 & 3991.08 & 1480.08 & 3991.16 & 1480.25 \\
\hline 5 & 4414.92 & 1559.15 & 4415.14 & 1559.39 \\
\hline Total & 18593.63 & 7158.23 & 18594.54 & 7159.12 \\
\hline
\end{tabular}

The third iteration is obtained from time (engine $1+$ engine to $2+$ engine 3 ) and time (engine to $7+$ engine to $6+$ engine to 5). For the third iteration $(\mathrm{k}=$ $3)$, the sequence generated from the system and manual calculation is the same, namely 5-4-3-2-1, so that the total time is 210.12 minutes.

- Iteration 4

The first and second time tables of iterations 4 , in Table 6:

Table 6. CDS fourth iteration

\begin{tabular}{|c|c|c|c|c|}
\hline \multirow[t]{2}{*}{ Job } & \multicolumn{2}{|c|}{$\begin{array}{l}\text { Total manual } \\
\text { processing time } \\
\text { (seconds) }\end{array}$} & \multicolumn{2}{|c|}{$\begin{array}{l}\text { Total processing time } \\
\text { (seconds) of the } \\
\text { system }\end{array}$} \\
\hline & $t^{k}{ }_{i 1}$ & $t^{K_{1,2}}$ & $t^{k}{ }_{i 1}$ & $t^{K}{ }_{i=2}$ \\
\hline 1 & 4455.96 & 2943.72 & 4456.24 & 2943.94 \\
\hline 2 & 5268.12 & 3210.6 & 5268.42 & 3210.90 \\
\hline 3 & 5773.08 & 3274.2 & 5773.30 & 3274.36 \\
\hline 4 & 5978.28 & 3467.28 & 5978.40 & 3467.48 \\
\hline 5 & 6503.16 & 3647.4 & 6503.46 & 3647.71 \\
\hline Total & 27978.6 & 16543.2 & 27979.81 & 16544.39 \\
\hline
\end{tabular}

The fourth iteration is obtained from time (machine 1 + engine $2+$ engine $3+$ engine 4 ) and time (engine 7 + engine $6+$ engine $5+$ engine 4 ). For the fourth iteration $(\mathrm{k}=4)$, the sequence generated from the system and manual calculation is the same, namely 5 4-3-2-1, so that the total time is 210.12 minutes.

- Iteration 5

Following is the first and second time table of iterations 5, in Table 7:

Table 7. The fifth Iteration of CDS

\begin{tabular}{|c|c|c|c|c|}
\hline \multirow[t]{2}{*}{ Job } & \multicolumn{2}{|c|}{$\begin{array}{l}\text { Total manual processing } \\
\text { time (seconds) }\end{array}$} & \multicolumn{2}{|c|}{$\begin{array}{l}\text { Total processing time } \\
\text { (seconds) of the system }\end{array}$} \\
\hline & $t^{K_{i} \mathbb{1}}$ & $t^{K}{ }_{1,2}^{K}$ & $t^{K}{ }_{i, 1}$ & $t^{k}{ }_{i, 2}$ \\
\hline 1 & 4594.19 & 4744.08 & 4594.49 & 4744.40 \\
\hline 2 & 5403.36 & 5127.24 & 5403.72 & 5127.64 \\
\hline 3 & 5915.16 & 5416.32 & 5915.39 & 5416.54 \\
\hline 4 & 6125.16 & 5709.36 & 6125.33 & 5709.58 \\
\hline 5 & 6657.12 & 6035.88 & 6657.52 & 6063.30 \\
\hline Total & 28694.99 & 27032.88 & 28696.44 & 27061.45 \\
\hline
\end{tabular}

The fifth iteration is obtained from time (engine $1+$ engine to $2+$ engine to $3+$ engine to $4+$ engine to 5 ) and time (engine to $7+$ engine to $6+$ engine to $5+$ engine to 4 to engine 3$)$. For the fifth iteration $(\mathrm{k}=$ $5)$, the sequence generated from the system and manual calculation is the same, namely $1-5-4-3-2$, so that the total time is obtained at 232.08 minutes.

- Iteration 6

The following is the first and second time table of iterations 6 , shown in Table 8:

Table 8. Sixth Iteration of CDS

\begin{tabular}{|c|c|c|c|c|}
\hline \multirow[t]{2}{*}{ Job } & \multicolumn{2}{|c|}{$\begin{array}{c}\text { Total manual processing } \\
\text { time (seconds) }\end{array}$} & \multicolumn{2}{|c|}{$\begin{array}{l}\text { Total processing time } \\
\text { (seconds) of the system }\end{array}$} \\
\hline & $t^{K_{i, 1}}$ & $t^{K_{1,2}^{2}}$ & $t^{K}{ }_{i, 1}$ & $t^{k}{ }_{1,2}$ \\
\hline 1 & 4889.03 & 4789.44 & 4889.41 & 4789.86 \\
\hline 2 & 5701.2 & 5177.04 & 5701.63 & 5177.45 \\
\hline 3 & 6206.88 & 5476.67 & 6207.16 & 5476.98 \\
\hline 4 & 6452.76 & 5769.83 & 6453.04 & 5770.06 \\
\hline 5 & 7032.24 & 6106.92 & 7032.71 & 6107.35 \\
\hline Total & 30282.11 & 27319.9 & 30283.94 & 27321.69 \\
\hline
\end{tabular}

The sixth iteration is obtained from time (engine $1+$ engine to $2+$ engine to $3+$ engine to $4+$ engine to 5 + engine to 6 ) and time (engine to $7+$ engine to $6+$ engine to $5+$ engine to $4+$ engine to $3 \mathrm{rd}+2$ nd machine). For the sixth iteration $(\mathrm{k}=6)$, the sequence generated from the system and manual calculation are the same, namely $5-4-3-2-1$, so that the total time is 210.12 minutes.

After obtaining all the iterations from the CDS algorithm, the makespan value data is collected from all the iterations. From the six iterations, the makespan value table is obtained, then the smallest makespan value is selected. So that the optimal total time is obtained by 210.12 with the sequence of job processing 5-4-3-2-1. And from the results of manual calculations and calculations using Microsoft Excel, the minimum makespan value is 210.12 .

Table 9. Makespan value for each iteration

\begin{tabular}{|c|c|c|}
\hline Iteration to & Product order & Makespan \\
\hline 1 & $5-4-3-2-1$ & 210.12 \\
\hline 2 & $1-5-4-3-2$ & 232.08 \\
\hline 3 & $5-4-3-2-1$ & 210.12 \\
\hline 4 & $5-4-3-2-1$ & 210.12 \\
\hline 5 & $1-5-4-3-2$ & 232.08 \\
\hline 6 & $5-4-3-2-1$ & 210.12 \\
\hline
\end{tabular}

\subsection{Evaluation and Comparison}

The comparison results are the results of manual calculations compared to the results obtained from the system, from the results obtained the accuracy of calculations made by the system. The comparison data is obtained from the total time in each iteration on the first and second machines from manual and system calculations. 
Table 10. Results of comparison

\begin{tabular}{|c|c|c|c|c|}
\hline \multirow{2}{*}{ Iteration } & \multicolumn{2}{|c|}{$\begin{array}{c}\text { Total manual processing } \\
\text { time (seconds) }\end{array}$} & \multicolumn{2}{c|}{$\begin{array}{c}\text { Total processing time } \\
\text { (seconds) of the system }\end{array}$} \\
\cline { 2 - 5 } & $t^{k}{ }_{i, 1}$ & $t^{k}{ }_{i, 2}$ & $t^{k}{ }_{i, 1}$ & $t^{k}{ }_{i, 2}$ \\
\hline 1 & 7817.23 & 4854.98 & 7817.23 & 4854.98 \\
\hline 2 & 8103.95 & 6441.82 & 8104.48 & 6442.49 \\
\hline
\end{tabular}

$$
\begin{aligned}
& \text { comparison } t^{k}{ }_{i, 1}=\frac{\text { total } t^{k}{ }_{i, 1} \text { manual }}{\text { total } t^{k}{ }_{i, 1} \text { sistem }} \times 100 \%=\frac{121470,5}{121476,4} \times 100 \%=99,99 \% \\
& \text { comparison } t^{k}{ }_{i, 2}=\frac{\text { total } t^{k}{ }_{i, 2}^{k} \text { manual }}{\text { total } t^{k}{ }_{i, 2} \text { sistem }} \times 100 \%=\frac{121470,5}{121476,4} \times 100 \%=99,96 \%
\end{aligned}
$$

The results of the comparison show that the system has accuracy $t^{k}$ i.1 amounting to $99,99 \%$ dan $t^{k}{ }_{i, 2}$ amounting to $99.96 \%$ of manual calculations, which means the system has a level of accuracy that can be said to be almost the same as manual calculations.

\section{Conclusion}

Production time optimization by scheduling using Campbell Dudek and Smith (CDS) algorithm can optimize production time because the CDS algorithm uses the calculation of process time comparisons on each machine in the company by prioritizing the smallest processing time for scheduling, and by repeating 6 iterations to determine the smallest processing time. By prioritizing the smallest processing time, the minimum production process time is produced. The implementation of the CDS algorithm to optimize the company's production time with 12 products produced in each type of pan produces six iterations and from the six iterations the minimum value of makespan is 210.12 minutes with a work order of 20 - grid 18 - grid 16 griddle 14 - griddle 12 . From that result, the minimum makespan value is 210.12 minutes with the order of the skillet product 20 - skillet 18 - skillet 16 - skillet 14 skillet 12 . The accuracy of application test results shows $99.99 \%$ for the first time and $99.96 \%$ for the second time compared to manual calculations. From these results, it can help the production process be more optimal.

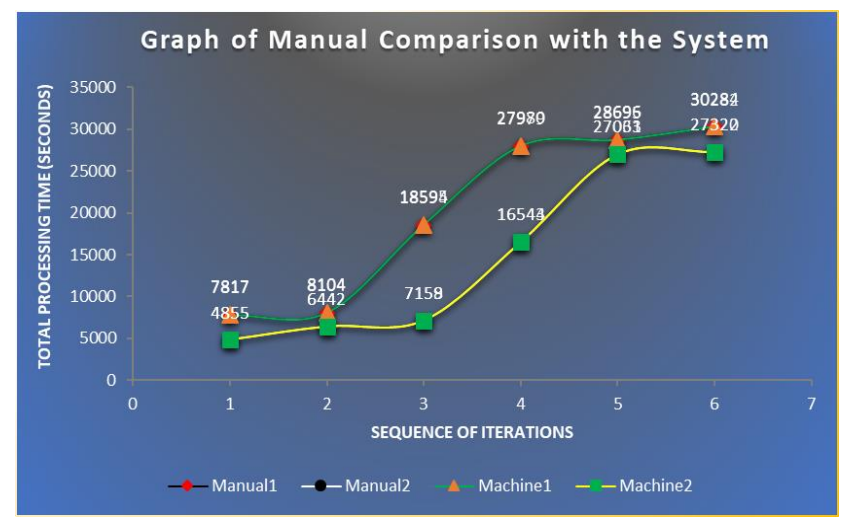

Fig. 3. Graph of manual comparison with the system

\section{References}

1. J. Yongqing, P. Fucheng, Improved Heuristic Algorithm for Modern Industrial Production Scheduling, The 9th International Conference on Modelling, Identification and Control (ICMIC 2017) Kunming China (2017)

2. Bouzidi, M.E. Riffi, Cat Swarm Optimization to Solve Job Shop Scheduling Problem, IEEE 2, 47995979 (2014)

3. C.W. Moreno, Optimization in Production Operations Optimal "Lean Operations" in Manufacturing, Advanced Process Management 513, 469-8629 (2006)

4. L.W. Cesari, Production Time Optimization and Periodic Analysis on Graf Loop Production System using the Aljanar MAX-PLUS Linear Equation System, Perpustakaan Yogyakarta, (2016)

5. J. Yao, Z. Deng, Scheduling Optimization in the Mass Customization of Global Producer Services, IEEE Transactions on Engineering Management, 0018-9391 (2015)

6. Kurnia, R. Yasra, V.M. Afma, Production Scheduling using Campbell Dudek Smith on Evertech Laser Marking Machines to Minimize Makespan, Profesiensi, 93-103 (2013)

7. M. Alharkan, Algorithms for Sequencing and Scheduling, Riyadh, Saudi Arabia, (2005)

8. Boiko, V. Shendryk, O. Boiko, Information Systems for Supply Chain Management: Uncertainties,Risks And Cyber Security, Procedia Computer Science 149, 65-70 (2019)

9. L.M. Ellram, M.L.U. Murfield, Supply Chain Management in Industrial Marketing-Relationships Matter," Industrial Marketing Management 03 (007), 0019-8501 (2019) 